\title{
A PESTICIDE RATING SYSTEM FOR MONITORING AGRICHEMICAL INPUTS IN NEW ZEALAND HORTICULTURE
}

\author{
J.T.S.WALKER ${ }^{1}$, A.J. HODSON ${ }^{2}$, T.A. BATCHELOR ${ }^{3}$, \\ D.W. MANKTELOW ${ }^{1}$ and A.R. TOMKINS ${ }^{4}$
}

\author{
${ }^{I}$ The Horticulture and Food Research Institute of New Zealand Ltd, \\ Hawke's Bay Research Centre, Private Bag 1401, Havelock North \\ ${ }^{2}$ Taylor, Pinchin and Associates Ltd, PO Box 55, Hastings \\ ${ }^{3}$ ENZA New Zealand (Int.), PO Box 1011, Hastings \\ ${ }^{4}$ Ruakura Research Centre, Private Bag 3123, Hamilton
}

\begin{abstract}
A Pesticide Rating System has been developed to monitor changes in agrichemical use by New Zealand's fruit industries. The system uses authoritative data to derive points-based ratings of toxicity for three categories of pesticide exposure to consumers, orchard workers, and the environment. A proposed fourth category, on policy and market issues, would assign objective measures to market concerns relating to specific agrichemicals. 'Consumer Points' are determined using World Health Organization acceptable daily intake data, while worker risk is assessed from an existing User Hazard Classification scheme. 'Enviro Points' for a pesticide are determined by assessing its movement, degradation and potential for bio-accumulation in the environment together with its toxicity to mammals, birds, bees and beneficial insects. Points are summed to produce an overall index of risk for each product application. The system, which has been developed in consultation with growers, consumers, agrichemical manufacturers, regulatory authorities and environmental groups, is presented with examples of pesticide use in horticultural crops.
\end{abstract}

Keywords: pesticide rating system, horticultural crops, environment, consumers, workers

\section{INTRODUCTION}

The rapid expansion of the area planted in fruit and vine crops in New Zealand has resulted in a doubling of the quantity of insecticide and fungicide used between 1983 and 1987 (MacIntyre et al. 1989). Although good progress has recently been achieved in reducing insecticide use in the kiwifruit sector (Steven et al. 1994), integrated pest management strategies are not widely used in other fruit crops. Now, with increasing consumer concern over pesticide residues in food, and the impact of crop protection practices on the environment, our fruit industries need to develop strategies to minimise pesticide use through greater adoption of integrated pest and disease management systems. Specifically, they need to minimise pesticide use by avoiding unnecessary applications, optimising pesticide timing and making greater use of selective and more benign pesticides. They must also be able to demonstrate performance towards lower pesticide use and safer crop protection practices.

Historically, growers have chosen pesticides based primarily on crop safety from phytotoxicity, product efficacy, price, bee safety and product compatibility. Less consideration has been given to the potential side effects of pesticides on humans or the environment, although some factors are addressed through official pesticide registration processes, withholding periods and crop re-entry times. Detailed information on the properties of pesticides is often not readily available, or easily assimilated, making it 
difficult for growers to determine the relative risks to humans or the environment when deciding which pesticide to use. Growers' crop protection records are also difficult to interpret and, until these were accessible through computer databases, it was difficult to summarise pesticide use statistics for each sector. The use of a single numerical value to integrate this complex information for each product, together with pesticide use data, has merit for growers and consultants involved with pest management decisions. It can also be used to demonstrate environmental and consumer benefits from producing fruit using different crop protection regimes.

A numerical system for assessing the impact of pesticides on workers, consumers and the environment was developed by Kovachet al. (1992) based on the principle that Risk = Toxicity $x$ Exposure. By summing separate worker, consumer and environment components, they assigned a single Environmental Impact Quotient (EIQ), or number, for each pesticide. This concept was developed further (Reus and Pak 1993; Penrose et al. 1994), but Dushoff et al. (1994) considered the environmental effects of each pesticide too complex to be summarised by a single number. None of the published systems account for all of the environmental impacts of pesticide use which requires more complex simulation modelling (van der Werf 1996). However, points-based systems are already being used by growers in several countries (Levitanet al. 1995) and a similar approach may be appropriate for our fruit industries.

A simple, effective pesticide rating system (PRS) is required by our horticultural sector to monitor and quantify changes in agrichemical use and improvements in its environmental performance. This paper reports on the development of a PRS to assist our growers in making decisions on pesticide use. The system can also be used at an industry level and in this paper is used to compare pesticide use in pipfruit, kiwifruit, grapes and summerfruit. It is also used to compare ratings associated with crop protection practices in conventional, Integrated Fruit Production or 'IFP' (Batchelor et al. 1997) and experimental 'organic' programmes on apple crops.

\section{METHODS}

The proposed PRS is based on the EIQ model (Kovach et al. 1992) using their premise that: Risk = Toxicity $\mathrm{x}$ Exposure . It consists of consumer, orchard worker, and environment components which are outlined in Fig. 1. Each agrichemical is allocated points based on its relative toxicity, with more points indicating greater hazard. Points for each agrichemical application made during the season are accumulated.

Key factors in the determination of 'Consumer Points' are derived from published World Health Organisation toxicological data for each agrichemical. The Theoretical Maximum Daily Intake (TMDI) as a percentage of acceptable daily intake (ADI) is an estimate of the proportion of the ADI that is accounted for from just the consumption of, for example pipfruit, by a person of average weight, eating an average amount of pipfruit. 'Worker Points' are derived from the classification described in the Toxic Substances Act 1979 given in the User Safety Advisory Section of the 1995 edition of the New Zealand Agrichemical Manual (Fussell and Walton 1995). Chronic toxicity to workers is derived from the No Observed Effect Level (NOEL) for each chemical.

'Enviro Points' are divided into two categories, acute toxicity and fate. Toxicity points are accumulated from product information for four groups of non-target organisms including rabbits, birds, bees and beneficial insects. Environmental fate reflects the potential for a chemical to move through the soil profile and contaminate water sources, its half life (i.e. persistence) and the potential for bio-accumulation. A fourth category, 'Market Policy Points', dealing with market concerns about individual products, is still under development and may be included in a subsequent iteration of the PRS.

We propose that each of the three risk categories is equally weighted until any wider debate establishes justification for differential weightings. Within each category the points range from $0-10$, but in practical terms consumer risk points are limited to 5 , as the use of extremely hazardous compounds is not permitted on food crops. Therefore, operationally, the maximum PRS points possible for an insecticide or fungicide is 25 . Because herbicides are not applied to fruit they incur no consumer points and carry a theoretical maximum of 20 points. 


\section{PESTICIDE RATING SYSTEM}

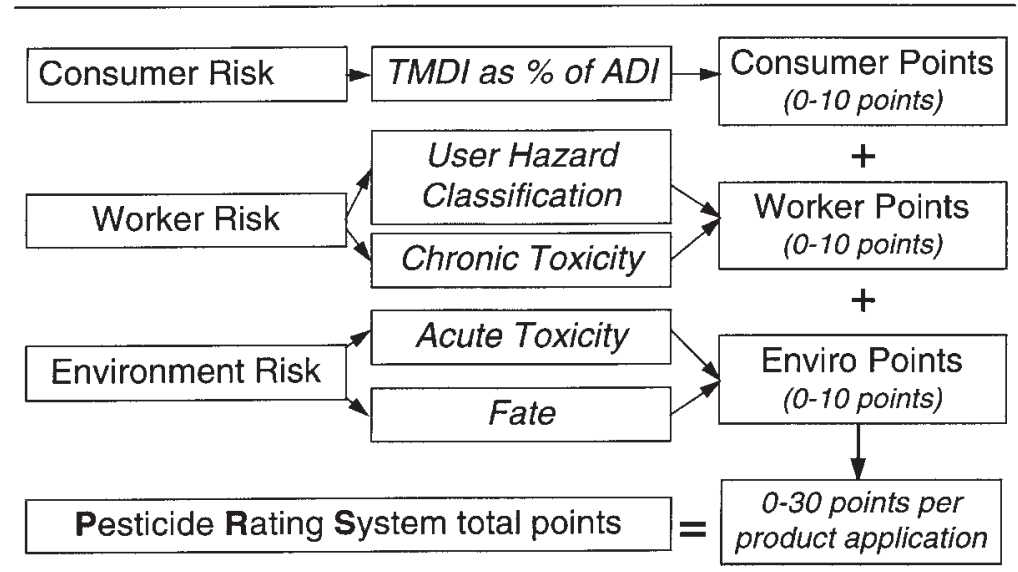

FIGURE 1: Key components and points structure of the proposed Pesticide Rating System. TMDI = the Theoretical Maximum Daily Intake: ADI $=$ the Acceptable Daily Intake (WHO classifications).

\section{RESULTS}

Software has been developed to read Paradox database files, one containing growers' pest and disease control records and another containing the PRS pesticide profile data sheets on each product registered for use on key horticultural crops in New Zealand. The software can be used to identify a wide range of pesticide use statistics and PRS points at a grower, regional or national level for crops where pesticide application recording is mandatory, e.g. ENZA's Pest Control Record Book for pipfruit and KNZ's (Kiwifruit New Zealand) Spray Diary for kiwifruit.

\section{Inter-crop comparisons}

The software was used to examine pesticide use and PRS scores in various crops. Note that data from kiwifruit is for conventionally grown fruit rather than fruit grown following 'Kiwigreen' practices. The results of these analyses are shown in Table 1.

TABLE 1: The average seasonal PRS scores with lower and upper quartiles for pesticide use in horticultural crops.

\begin{tabular}{|c|c|c|c|c|c|c|}
\hline \multirow[t]{2}{*}{ Crop } & \multirow[t]{2}{*}{ District } & \multirow[t]{2}{*}{ Season } & \multirow{2}{*}{$\begin{array}{l}\text { No. of } \\
\text { growers }\end{array}$} & \multirow{2}{*}{$\begin{array}{l}\text { Mean } \\
\text { PRS } \\
\text { score }\end{array}$} & \multicolumn{2}{|c|}{ Quartiles } \\
\hline & & & & & Lower & Upper \\
\hline Apple & $\begin{array}{l}\text { Hawkes Bay } \\
\text { and Nelson }\end{array}$ & $1994 / 95$ & 1080 & 414 & 395 & 502 \\
\hline Pear & Hawkes Bay & $1994 / 95$ & 109 & 273 & 216 & 331 \\
\hline Peach & Hawkes Bay & $1995 / 96$ & 130 & 95 & 69 & 120 \\
\hline Plum & Hawkes Bay & $1995 / 96$ & 44 & 65 & 41 & 85 \\
\hline Kiwifruit & Nelson & $1992 / 93$ & 65 & 122 & 83 & 136 \\
\hline Grape & Hawkes Bay & $1992 / 93$ & 27 & 83 & 62 & 92 \\
\hline
\end{tabular}

Pesticide use varies substantially within our horticultural sector. Apples have a high frequency of pesticide use and consequently score significantly more PRS points than 
other crops in the regions investigated. This reflects the stringent phytosanitary procedures that are required by this sector to maintain market access. Crops using fewer insecticides have significantly lower scores showing that, with the present structure, commonly used organophosphate (OP) insecticides incur high PRS scores compared to fungicides. Accordingly, a greater reduction in PRS score may be achieved by a small reduction in OP insecticide use than through a substantial reduction in fungicide use. Correspondingly, increased fungicide use in wet seasons will not greatly affect the points accumulation. The variability of PRS points within each sector is similar and is related more to variation in the frequency of applications than to the use of products with lower PRS scores. The high level of variability in PRS scores suggests that significant progress in reducing pesticide use could be achieved by ensuring that growers who are 'high users' are informed of 'low use' practices.

Programme comparisons - apple case study

The apple industry in Hawkes Bay and Nelson has a relatively high level of pesticide use (Table 1) which is determined, in part, by the climate (wet spring conditions requiring frequent use of fungicides for apple blackspot (Venturia inaequalis) control) and by phytosanitary constraints in important markets. For example, a stringent code of practice, based on frequent use of broad-spectrum OP insecticides, has been implemented to ensure that USDA phytosanitary standards are met (ENZA's USA Code of Practice). A frequency distribution of growers' PRS points highlights the variation in crop protection practices (Fig. 2) and reflects similar variations in pesticide use elsewhere (Penroseet al. 1994). A high proportion of these growers were producing export quality crops so many of those incurring more than 400 PRS points were either making unnecessary applications or were confronted with higher levels of pest and disease pressure. The PRS can therefore be used to highlight over-use of agrichemicals within conventional production by identifying high scoring crop protection programmes.

An IFP programme for pipfruit (NZ IFP-P), to address consumer and market

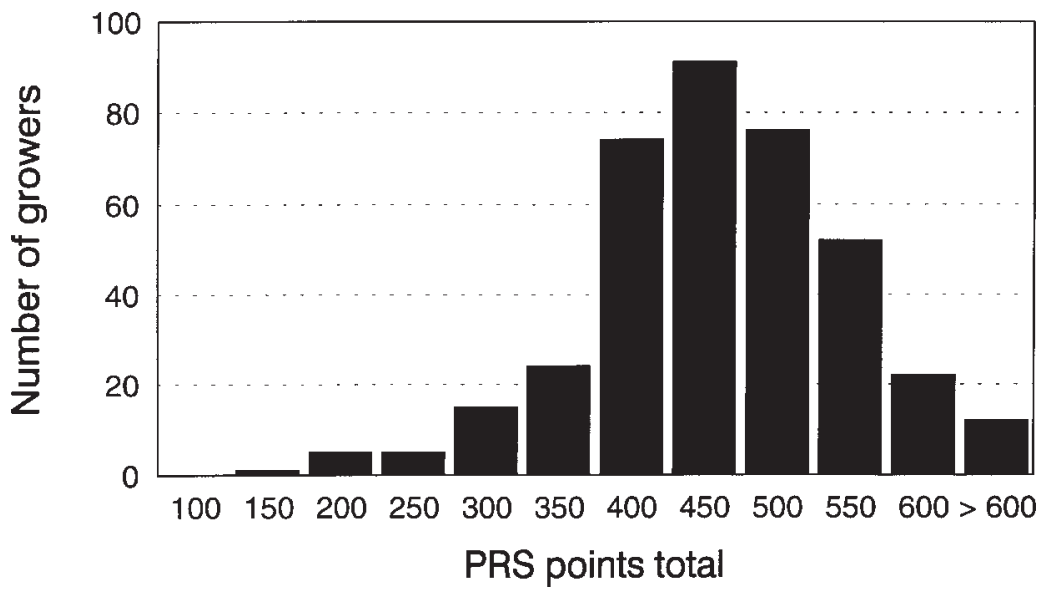

FIGURE 2: The distribution of PRS points for insecticide and fungicide use on Braeburn apples in Hawkes Bay and Nelson in the 1994-95 season.

concerns over pesticide use, has been developed and is being tested by growers (Batchelor et al. 1997). In this programme pesticides are applied only in response to monitored pest and disease threshold levels. This, together with the use of less toxic and selective insect growth regulator insecticides in place of OP's, greatly reduces the PRS points incurred (Table 2). PRS point scores are likely to be even lower with organic fruit 
production where pests and diseases are typically managed with oils,Bacillus thuringiensis, copper and sulphur and other cultural techniques.

TABLE 2: The mean PRS seasonal scores for three different apple production systems showing lower and upper quartiles for conventional and IFP orchards and an expected range (*) for organic fruit production systems.

\begin{tabular}{lcccc}
\hline $\begin{array}{l}\text { Production } \\
\text { system }\end{array}$ & Season & Mean PRS & \multicolumn{2}{c}{ Range } \\
\hline score & Lower & Upper \\
\hline Conventional $^{1}$ & $1994-95$ & 414 & 395 & 502 \\
Bntegrated $^{2}$ & $1996-97$ & 268 & 214 & 288 \\
\hline
\end{tabular}

${ }^{1}$ Based on 1994-95 ENZA spray diaries ( $\left.\mathrm{n}=1080\right)$, Nelson and Hawkes Bay.

2 Based on 1996-97 ENZA Pest Control Record Books $(n=68)$ for Hawkes Bay IFP growers.

${ }^{3}$ Based on HortResearch trials in Hawkes Bay.

\section{DISCUSSION}

Exporters of fruit from New Zealand require their growers to supply records of all agrichemical sprays applied on crops. In some cases, this information is stored on databases to ensure that product traceback requirements can be achieved and compliance demonstrated. In their unprocessed form these spray diaries are difficult to interpret but software incorporating the PRS enables pesticide use in each sector to be readily analysed with respect to current use and longer term trends. This is particularly useful when our fruit industries are trying to reduce pesticide use and improve environmental performance. Our customers overseas have asked us to supply high quality fruit produced in an environmentally responsible manner. By comparing the historical use of agrichemicals with use under the new crop protection and environmental guidelines, we will be able to show compliance with their requests.

We make no apology for pursuing a simple, semi-quantitative approach in the development of a PRS for the New Zealand fruit industry, provided the limitations are recognised and minor differences between the numerical scores of products do not become the focus for undue debate. A numerical score, and their summation for each product application, can be used to set and monitor a grower's, or an entire fruit industry's, performance towards a goal of reducing the adverse environmental effects associated with pesticide use. While the PRS can be seen as a performance indicator of changing crop protection practices, it makes no attempt to address the issues of pesticide cost and efficacy.

In the development of the PRS we have consulted extensively with growers, producer boards, agrichemical manufacturers, regulatory authorities and environmentalists to reach a negotiated compromise on the components, their values and scaling of toxicity values. Some of the problems associated with the EIQ system (Kovachet al. 1992) have been addressed, e.g. the minimum score for a completely benign product is now zero. The application rate has been specifically excluded as we do not want to encourage the use of rates below registered label rates for reasons of product efficacy and resistance management. We also feel that lower rates do not necessarily lessen the impact of many pesticides on populations of beneficial species. Timing of pesticide application is not included within this version of the PRS but will be addressed in subsequent iterations.

There are inherent short-comings in points-based systems that attempt to describe a whole range of complex toxicological and environmental parameters. However, this system has merit in assisting and monitoring our fruit industries' performance towards decreased pesticide use and greater sustainability in our horticultural production systems. The examples given show that the PRS has value in planning strategies to achieve lower pesticide use, and as a mechanism to demonstrate progress towards this goal. For 
growers, the PRS has value as a crop protection planning tool, enabling selection of products with fewer points. It may also encourage growers and industry agencies to adopt new technologies which may help maintain the international competitiveness of our fruit industries.

\section{ACKNOWLEDGEMENTS}

The authors would like to acknowledge ENZA New Zealand (International), Zespri International Ltd., Heinz-Wattie Ltd. and Montana Wines for their permission to use crop protection information. We would also like to acknowledge MAFPolicy and HortResearch funding support for this project. We extend our thanks to the many people within grower, agrichemical and environmental groups who have commented on, or have been involved with, the development of the PRS.

\section{REFERENCES}

Batchelor, T.A., Walker, J.T.S., Manktelow, D.W.L., Park, N.M. and Johnson, S.R., 1997. New Zealand integrated fruit production for pipfruit - charting a new course. Proc. 50th N.Z. Plant Prot. Conf.: (this volume).

Dushoff, J., Caldwell, B. and Mohler, C.L., 1994. Evaluating the environmental effects of pesticides: a critique of the environmental impact quotient. Am. Entomol. 40:180184.

Fussell, A. and Walton, T., 1995. New Zealand Agrichemical Manual, Master Edition, Wham Chemsafe Ltd.

Kovach, J., Petzoldt, C., Degni, J. and Tette, J., 1992. A method to measure the environmental impact of pesticides.New York's Food Life Sci. Bull. 139, New York State Agriculture Experiment Station, Geneva, New York. 8p.

Levitan, L., Merwin, I. and Kovack, J., 1995. Assessing the relative environmental impacts of agricultural pesticides: the quest for a holistic method. Agric. Ecosyst. Environ. 55:153-168.

MacIntyre, A.A., Alison, N. and Penman, D.R., 1989. Pesticides: Issues and Options for New Zealand. Wellington. Ministry for the Environment. 208p.

Penrose, L.J., Thwaite, W.G. and Bower, C.C., 1994. Rating index as a basis for decision making on pesticide use reduction and for accreditation of fruit produced under integrated pest management. Crop Prot. 13: 146-152.

Reus, J.A.W.A., and Pak, G.A., 1993. An environmental yardstick for pesticides. Med. Fac. Landbouww. Univ. Gent. 58/2a: 249-255.

Steven, D., Tomkins, A.R., Blank, R.H. and Charles, J.G., 1994. A first-stageintegrated pest management system for kiwifruit. Proc. Brighton Crop Prot. Conf.: 135-142.

van der Werf, H.M.G., 1996. Assessing the impact of pesticides on the environment. Agric. Ecosyst. Environ. 60: 81-96. 